University of Massachusetts Amherst

ScholarWorks@UMass Amherst

Chemistry Department Faculty Publication

Series

Chemistry

2021

\title{
Circadian Alterations Increase with Progression in a Patient- Derived Cell Culture Model of Breast Cancer
}

Hui-Hsien Lin

University of Massachusetts Amherst

Stephanie R. Taylor

Colby College

Michelle E. Farkas

University of Massachusetts Amherst

Follow this and additional works at: https://scholarworks.umass.edu/chem_faculty_pubs

\section{Recommended Citation}

Lin, Hui-Hsien; Taylor, Stephanie R.; and Farkas, Michelle E., "Circadian Alterations Increase with Progression in a Patient-Derived Cell Culture Model of Breast Cancer" (2021). Clocks \& Sleep. 1482. https://doi.org/10.3390/clockssleep3040042

This Article is brought to you for free and open access by the Chemistry at ScholarWorks@UMass Amherst. It has been accepted for inclusion in Chemistry Department Faculty Publication Series by an authorized administrator of ScholarWorks@UMass Amherst. For more information, please contact scholarworks@library.umass.edu. 


\title{
Circadian Alterations Increase with Progression in a Patient-Derived Cell Culture Model of Breast Cancer
}

\author{
Hui-Hsien Lin ${ }^{1}$, Stephanie R. Taylor ${ }^{2, *(D)}$ and Michelle E. Farkas ${ }^{1, *(D)}$ \\ 1 Department of Chemistry, University of Massachusetts Amherst, Amherst, MA 01003, USA; hlin@umass.edu \\ 2 Department of Computer Science, Colby College, Waterville, ME 04901, USA \\ * Correspondence: srtaylor@colby.edu (S.R.T.); farkas@chem.umass.edu (M.E.F.)
}

check for

updates

Citation: Lin, H.-H.; Taylor, S.R.; Farkas, M.E. Circadian Alterations Increase with Progression in a Patient-Derived Cell Culture Model of Breast Cancer. Clocks\&Sleep 2021, 3, 598-608. https://doi.org/10.3390/ clockssleep3040042

Received: 27 July 2021

Accepted: 28 October 2021

Published: 12 November 2021

Publisher's Note: MDPI stays neutral with regard to jurisdictional claims in published maps and institutional affiliations.

Copyright: (c) 2021 by the authors. Licensee MDPI, Basel, Switzerland. This article is an open access article distributed under the terms and conditions of the Creative Commons Attribution (CC BY) license (https:// creativecommons.org/licenses/by/ $4.0 /)$.

\begin{abstract}
Circadian rhythm disruption can elicit the development of various diseases, including breast cancer. While studies have used cell lines to study correlations between altered circadian rhythms and cancer, these models have different genetic backgrounds and do not mirror the changes that occur with disease development. Isogenic cell models can recapitulate changes across cancer progression. Hence, in this study, a patient-derived breast cancer model, the $21 \mathrm{~T}$ series, was used to evaluate changes to circadian oscillations of core clock protein transcription as cells progress from normal to malignant states. Three cell lines were used: H16N2 (normal breast epithelium), 21PT (atypical ductal hyperplasia), and 21MT-1 (invasive metastatic carcinoma). The cancerous cells are both HER2+. We assessed the transcriptional profiles of two core clock proteins, BMAL1 and PER2, which represent a positive and negative component of the molecular oscillator. In the normal H16N2 cells, both genes possessed rhythmic mRNA oscillations with close to standard periods and phases. However, in the cancerous cells, consistent changes were observed: both genes had periods that deviated farther from normal and did not have an anti-phase relationship. In the future, mechanistic studies should be undertaken to determine the oncogenic changes responsible for the circadian alterations found.
\end{abstract}

Keywords: breast cancer; cancer progression; circadian rhythm; metastatic cells; rhythmicity

\section{Introduction}

The circadian clock is a hierarchical timing system that regulates physiological, behavioral, and metabolic functions across a $24 \mathrm{~h}$ day-night cycle and maintains temporal tissue homeostasis in coordination with the external environment [1,2]. Peripheral clocks are entrained by a central core clock located in the suprachiasmatic nucleus (SCN) and are necessary for normal tissue functioning, including cell development [3,4]. At the molecular level, the core clock consists of a well-characterized transcriptional-translational feedback loop (TTFL), where CLOCK and BMAL1 bind to an E-box promoter to drive the expression of other clock genes, including CRY and PER. Subsequently, CRY and PER accumulate in the cytoplasm during the day to form complexes, which translocate back to the nucleus to suppress the activity of CLOCK and BMAL1 [2]. Disrupted circadian rhythms have been associated with different types of cancer, including but not limited to breast [5-8], colon [9], and prostate cancers [10]. For breast cancer, in particular, epidemiological studies have shown that long-term night shift workers have a higher risk of developing the disease [11-13]. Furthermore, both in vitro and in vivo studies have indicated that mutation or dysregulation of clock genes can lead to the initiation of breast tumor growth and metastases [5-8].

Among women in the United States, breast cancer is the most commonly diagnosed cancer type, with the second highest cancer death rate following lung and bronchus cancer [14]. Female breast tissue is subject to more frequent remodeling than other types [15]. For example, during pregnancy, lactation, and involution, the mammary epithelium undergoes multiple cycles of proliferation and cell death $[16,17]$. As a result, the mammary gland 
is more prone to abnormalities, which can result in cancer [18]. While it has been shown that genetic mutations and epigenetic modifications contribute to breast cancer progression and development $[19,20]$, the molecular mechanisms of such processes are still unclear.

Various breast cancer cell lines (e.g., MCF-7, MDA-MB-231, SKBR3, and many others) are frequently used for studying the disease and potential therapeutics for treating it [21-23]. Although these cellular models are generally categorized into different breast cancer subtypes [24], they each represent only a single stage of a progressive disease. As a complementary approach, a series of cell lines representing disease progression can be used. There are a few such models that have been used to study breast cancer development, including the MCF10 human isogenic series [25-27] and the 4T1 syngeneic mouse model $[28,29]$. While each represents different stages of cancer and can be related to human disease, the MCF10 series was derived via laboratory-based genetic manipulations (including an H-Ras mutation rarely found in breast cancer patients), and the 4T1 series originated from a single, spontaneously arising mammary tumor in a BALB/c mouse. Neither may truly reflect the natural evolution of human breast cancer.

Among progressive cancer models, the $21 \mathrm{~T}$ series of cells is particularly relevant, since each cell type was isolated from the same patient, who originally had infiltrating and intraductal carcinoma and later developed metastases to the lung [30]. Four cell lines comprise the model: H16N2, tumor-adjacent non-cancerous breast cells; 21PT, Atypical Ductal Hyperplasia (ADH) cells, which are non-tumorigenic and non-metastatic; 21NT, Ductal Carcinoma In Situ (DCIS), which are tumorigenic and non-metastatic; and 21MT, Invasive Metastatic Carcinoma (IMC), which are both tumorigenic and metastatic. Two distinct populations exist within the 21MT cell line, which was further separated into 21MT-1 and 21MT-2. 21MT-1 are highly heterogeneous, tend to grow in clusters, and do not form confluent monolayers, while 21MT-2 are homogeneous polygonal cells that grow as monolayers [30]. All cancerous cells of the 21T series overexpress ERBB2 compared to normal H16N2 cells [30]. ERBB2 encodes the human epidermal growth factor receptor 2 (HER2), which is overexpressed, amplified, or both in several human malignancies including breast, ovarian, and colon cancers [31]. Overexpression of HER2 in human tumor cells is closely associated with increased angiogenesis, higher rates of cell survival, and poor clinical outcomes [32].

Disruption of circadian rhythms has been shown to trigger cancer development, and vice versa, malignant transformations have led to disturbances of circadian clocks $[5-8,13]$. In one of our previous studies, we showed that circadian clocks are disrupted across the MCF10 series of cells representing human breast cancer [33]. We found that from benign to metastatic states, PER2 exhibited relatively stable oscillations compared to BMAL1, whose periods were altered over a wide circadian range. As mentioned above, while the MCF10 series represents progressive stages of breast cancer, it originated with an H-Ras mutation, not commonly found in patients with the disease. To evaluate circadian changes in a more relevant model, we used the human 21T series of cells in the present study. This work represents the first assessment of circadian oscillations in a patient-derived model of breast cancer.

We used three cell lines from the 21T series, H16N2, 21PT, and 21MT-1, representing disease progression from benign to metastatic, to determine changes in the expression profiles of core circadian clock genes. We focused on a positive and negative component of the molecular clock oscillator, BMAL1 and PER2, respectively. The mRNA expressions of BMAL1 and PER2 were tracked in a time-dependent manner via RT-PCR assessments. Our transcriptional data indicate that the non-oncogenic H16N2 cells possess robust circadian patterns, while 21PT and 21MT-1 have consistently less reliable rhythms, with altered characteristics. These results support our hypothesis that circadian rhythms deviate from normal when cells undergo malignant transformations. In further studies, a luciferase or fluorescent reporter should be used to track the promoter activity of clock genes and/or protein expression to generate high-resolution data for a complete assessment of circadian parameters in this model. 


\section{Results}

In the current study, we sought to evaluate circadian alterations in a progressive, patient-derived breast cancer model to ascertain whether changes occurred with disease status. The 21T series of cell lines is considered a unique experimental model of breast cancer progression, since there are no other models that originated from a single patient. We used three cell lines from the human breast cancer 21T series, H16N2, 21PT, and 21MT-1, which were isolated from a single patient and have the same genetic background but different characteristics. H16N2 is derived from the normal epithelia, 21PT is derived from atypical ductal hyperplasia, and 21MT-1 is derived from the pleural effusion of lung metastasis [30]. This is an excellent model to recapitulate the de novo processes arising during breast cancer evolution.

We focused on the expression of two core circadian clock components, one from the positive and the other the negative arm of the feedback loop, BMAL1 and PER2, respectively. mRNA expression of both was evaluated for each of the three 21T cell lines, using RT-PCR (Figure 1), with sampling once every four hours from three biological replicates per cell line, over the course of two cycles from two separate experiments. We sought to determine whether each time series was rhythmic and, if so, its circadian properties (such as peak time; Table 1). To assess rhythmicity, we chose multiple, complementary methods that allowed for replicates and were flexible with respect to waveform and missing data: RAIN (arbitrary waveform) [34], a Lomb-Scargle permutation test (allows for missing data) [35], JTK-Cycle (compares reference curves to data) [36], and ECHO (fits data to a sine curve with amplitude changes over time) [37]. To assess circadian properties and the quality of rhythmicity, we fit each time series (with replicates) to a damped cosine curve.

(A) BMAL1

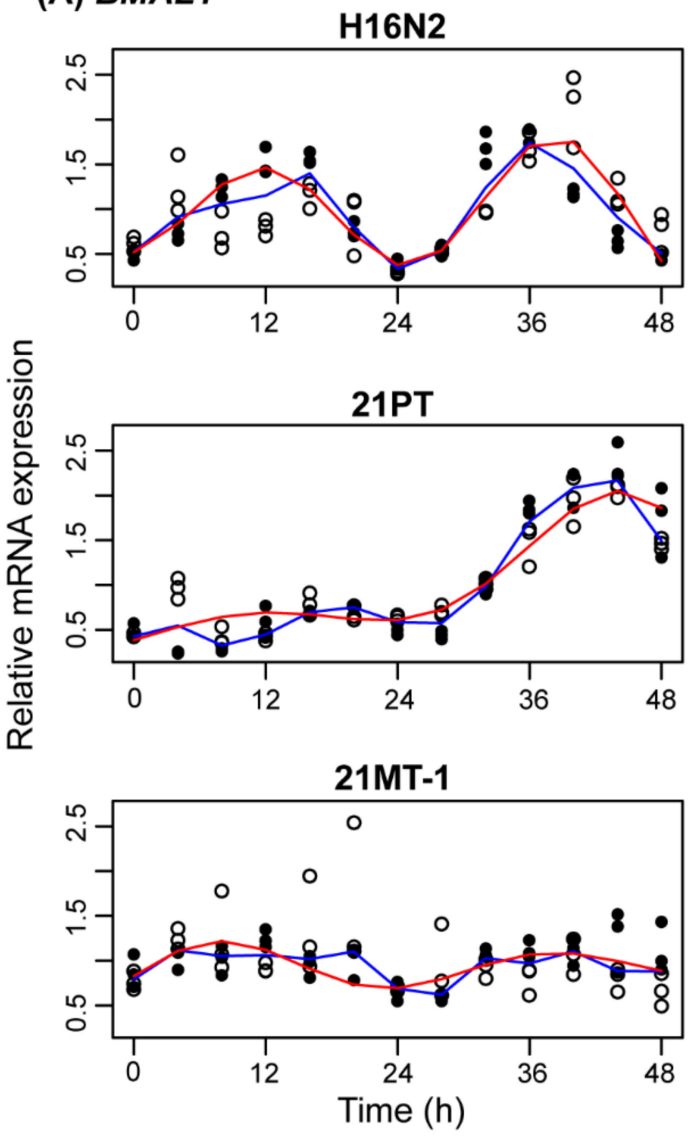

(B) PER2

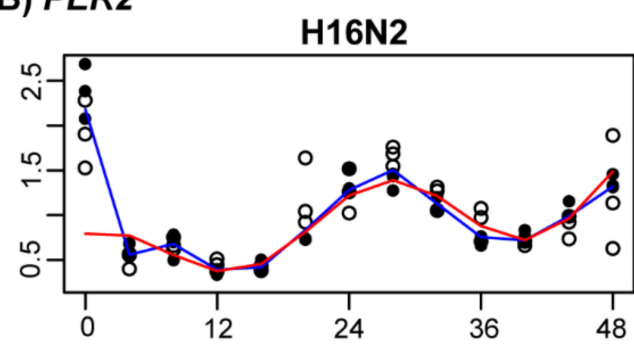

21PT

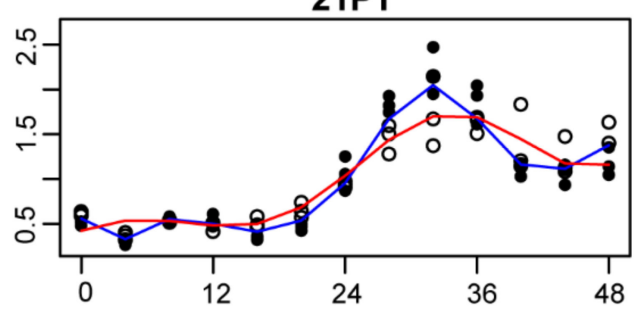

21MT-1

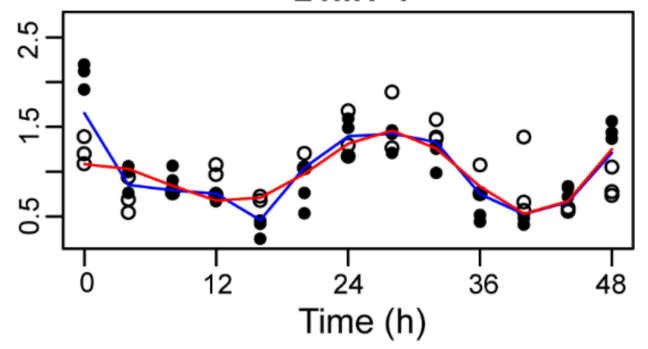

Figure 1. Relative mRNA expression of (A) BMAL1 and (B) PER2 across the 21T series of cells. Shown are the mRNA expression levels relative to the mean over time for each biological replicate (sample number (n) was 6 for all but 4 time points in 21MT-1, where $n=5)$. The experiment was conducted twice ( $n=3$ for each); open and closed circles are used to 
differentiate between the two. The median and best-fit damped cosine curves are shown in blue and red, respectively. The coefficient of determination $\left(\mathrm{R}^{2}\right)$ indicates a lack of fit for BMAL1 21MT-1 $\left(\mathrm{R}^{2}=-0.01\right)$, low-quality fits for PER2 in H16N2 $\left(\mathrm{R}^{2}=0.27\right)$ and PER2 in $21 \mathrm{MT}-1\left(\mathrm{R}^{2}=0.46\right)$, and medium-quality fits for the remaining curves $\left(\mathrm{R}^{2}=0.58\right.$ for $B M A L 1$ in H16N2, 0.84 for PER2 in 21PT, and 0.86 for BMAL1 in 21MT-1).

Table 1. Circadian parameters for BMAL1 and PER2 transcripts.

\begin{tabular}{ccccccc}
\hline \multirow{2}{*}{ Cell Line Transcript } & \multicolumn{2}{c}{ H16N2 } & \multicolumn{2}{c}{ 21PT } & \multicolumn{2}{c}{ 21MT-1 } \\
\cline { 2 - 7 } & BMAL1 & PER2 & BMAL1 & PER2 & BMAL1 & PER2 \\
\hline Baseline & $0.910 \pm 0.066$ & $0.485 \pm 0.050$ & $0.344 \pm 0.046$ & $0.254 \pm 0.040$ & NA & $0.876 \pm 0.065$ \\
Amplitude & $0.432 \pm 0.066$ & $0.309 \pm 0.052$ & $0.085 \pm 0.047$ & $0.173 \pm 0.032$ & NA & $0.208 \pm 0.061$ \\
Damping Rate (1/h) & $-0.015 \pm 0.005$ & $-0.011 \pm 0.006$ & $-0.050 \pm 0.018$ & $-0.028 \pm 0.058$ & NA & $-0.026 \pm 0.009$ \\
Phase (h) & $11.402 \pm 0.412$ & $26.952 \pm 0.362$ & $6.001 \pm 1.337$ & $31.473 \pm 0.711$ & NA & $27.033 \pm 0.479$ \\
Slope (/h) & $0.003 \pm 0.002$ & $0.018 \pm 0.002$ & $0.023 \pm 0.0029$ & $0.032 \pm 0.002$ & NA & $0.006 \pm 0.003$ \\
Period (h) & $26.546 \pm 0.526$ & $26.470 \pm 0.728$ & $35.745 \pm 1.905$ & $30.621 \pm 1.238$ & NA & $27.206 \pm 0.910$ \\
\hline
\end{tabular}

Error shown indicates standard error. Because curve fitting failed to represent the variance in the data (resulting in a lack of fit), characteristics associated with BMAL1 transcripts from 21MT-1 cells are not included (NA = not applicable).

All tests for rhythmicity indicated that the non-oncogenic H16N2 and non-tumorigenic, non-metastatic 21PT cells are rhythmic, where $p<0.001$ for each. The patterns for the $B M A L 1$ and PER2 transcripts from 21MT-1 cells were found to be rhythmic using most tests $(p<0.001)$, with the exception of the Lomb-Scargle permutation test for BMAL1, where $p=0.08$. Given that each data set was determined to be rhythmic by more than one test, we sought to further assess the characteristics of the oscillation patterns.

The normal breast epithelial H16N2 cells showed BMAL1 peaks at $\sim 12-16 \mathrm{~h}$ and $32-36 \mathrm{~h}$, while those for PER 2 were at $\sim 0-4 \mathrm{~h}$ and $\sim 24-28 \mathrm{~h}$. Hence, as expected for these positive and negative elements of the core clock, the phase difference between the two is approximately $12 \mathrm{~h}$, with oscillation patterns in opposition to each other. A slowly amplifying cosine curve with an increasing baseline fit the data relatively well, with the exception of the first time point for PER2 ( $\mathrm{R}^{2}=0.58$ for BMAL1 and 0.27 for PER2). Over $48 \mathrm{~h}$, the baseline of relative expression increased by 0.16 for BMAL1 and 0.86 for PER2, and the oscillations grew exponentially with rates of $0.02 / \mathrm{h}$ for $B M A L 1$ and $0.01 / \mathrm{h}$ for PER2 (Table 1, Tables S1 and S2). It also estimated peak times, where BMAL1 peaked $11.4 \mathrm{~h}$ and PER2 peaked $0.5 \mathrm{~h}$ into each cycle. The periods of both BMAL1 and PER2 were determined to be $26.5 \mathrm{~h}$ with a small estimation error (BMAL1 95\% CI: 25-27.7 h; PER2 95\% CI: 25-28.2 h).

The 21PT (non-tumorigenic and non-metastatic) cells showed oscillations with increasing amplitude. Visual inspection shows different phases from H16N2 with BMAL1 peaking at $\sim 16-20 \mathrm{~h}$ and $40-44 \mathrm{~h}$, while PER2 peaks at $\sim 8-12 \mathrm{~h}$ and $28-32 \mathrm{~h}$. We confirmed the rhythmic patterns were different with robustDODR applied to the time series after removing a linear trend $(p<0.001)$ [38], comparing each reporter across cell lines. Unlike in the normal cells, the transcriptional patterns here were not anti-phase but still had consistent changes (an approximately $8 \mathrm{~h}$ offset) for both BMAL1 and PER2 in all samples. Curve fitting also yielded reasonable fits for this cell line $\left(\mathrm{R}^{2}=0.86\right.$ for BMAL1 and 0.84 for PER2; Table 1, Tables S3 and S4). Compared to H16N2 cells, 21PT oscillations showed larger growth rates $(0.05 / \mathrm{h}$ for BMAL1 and $0.03 / \mathrm{h}$ for PER2) and steeper baselines (relative expression of BMAL1 increased by 1.09 over $48 \mathrm{~h}$ and PER2 by 1.54). The periods were also both longer than those of H16N2 transcripts, and there was more uncertainty in their estimates. The $95 \%$ confidence interval for the period of BMAL1 was $32-42 \mathrm{~h}$ for PER 2 was 28.4-34.3 h.

The 21MT-1 (tumorigenic, metastatic) cells showed oscillations with the least circadian characteristics. Compared to H16N2, the transcriptional patterns for both BMAL1 and PER2 were statistically different (robustDODR applied to linearly de-trended time series was $p<0.001)$. For $B M A L 1$, curve fitting failed to explain the variance in the data $\left(R^{2}=-0.01\right)$, so we do not report circadian parameters. For PER2, the time series for 21MT-1 shows less 
reliable estimates of parameters and is less sinusoidal $\left(R^{2}=0.46\right)$. Confidence intervals for the parameter estimates of PER2 are wide (95\% CI for period: $25-29.4 \mathrm{~h} ; 95 \% \mathrm{CI}$ for growth rate: $0.008-0.04$; Table S5). As in the 21PT cells, there were only $8 \mathrm{~h}$ between the peaks of $B M A L 1$ ( $8 \mathrm{~h}$ into each cycle) and PER2 ( $0 \mathrm{~h}$ into each cycle).

Additionally, to assess possible outcomes of mRNA expression changes at the protein level, we conducted time-course Western blot analyses for BMAL1 and PER2 with the three members of the 21T series of cells evaluated above (Figure S1). We fit each of the time series to damped cosine curves (Figure S2). Unlike for mRNA expression patterns, the sinusoidal curves could not be adequately fit to the time series, resulting in low goodness-of-fit measures. BMAL1 and PER2 were not observed to have a consistent phase relationship. While some of the statistical tests for rhythmicity identified particular time series as rhythmic (Tables S6 and S7), these results were too inconsistent to be considered reliable, as confirmed by visual inspection. This outcome is perhaps due to the nature of the technique, discussed further below.

\section{Discussion}

Various experimental platforms have been used to investigate the correlation between altered circadian rhythms and cancer development. These include murine models with spontaneously developing or implanted tumors [39,40], individual cancer cell lines representing specific subtypes (e.g., MDA-MB-231 or MCF7, as mentioned above) [8,41,42], and series of cells representing cancer progression (e.g., 4T1 or MCF10 series, as mentioned above) $[33,43]$. Studies using these models typically show that the expression of clock genes and/or proteins is disrupted (i.e., with arrhythmic oscillation patterns or diminished expression levels) via RT-PCR or Western blotting assessments. However, the data obtained do not reflect progressive oncogenic changes, since non-related cell lines have diverse genetic backgrounds, and the other models were not derived from patients carrying breast cancer. At the same time, assessments in clinical studies often involve only a single time point $[6,7,44,45]$. However, the nature of circadian rhythms is dynamic, and it is important to carry out direct comparisons as a function of time. We recognize the difficulty in obtaining/using patient samples in such a manner, and so, in the present study, we used primary and metastatic tumor cells along with those of the normal breast epithelium, derived from the same individual, to directly compare circadian properties in a time-dependent manner.

The foundation of circadian rhythmicity is the oscillation of molecular clocks for a period of approximately $24 \mathrm{~h}[46,47]$. During $24 \mathrm{~h}$ cycling, the peak times of positive and negative core clock regulators (i.e., BMAL1 and PER2, respectively) exhibit a nearly $12 \mathrm{~h}$ delay from one another, resulting in an anti-phase relationship [46]. While this is the case in healthy cells, in disease states, various alterations (e.g., changes to period [47], phase [48], and amplitude [49]) may occur. As shown in Figure 1 and Table 1, BMAL1 and PER2 transcripts from normal breast epithelial H16N2 cells showed rhythmic, anti-phase mRNA oscillations ( $\sim 12 \mathrm{~h}$ differences in peak times) with similar periods that were close to $24 \mathrm{~h}$ (estimates were $26.5 \mathrm{~h}$ for both) and good fits. However, longer and dissimilar periods (32.0 $\mathrm{h}$ for BMAL1 and $30.5 \mathrm{~h}$ for PER2 in 21PT; $30.5 \mathrm{~h}$ for BMAL1 and $27.1 \mathrm{~h}$ for PER2 in 21MT-1), and altered phase relationships ( $\sim \mathrm{h}$ shifts in peak times between BMAL1 and PER2) were found in the cancerous 21PT (ADH) and 21MT-1 (IMC) cells.

Few studies have analyzed changes in circadian characteristics using progressive cancer models, and this is the first such study in a disease-relevant model of breast cancer. Nonetheless, we compared our findings to those of others and strikingly observed similarities. For example, Relógio et al., discovered that metastatic human skin and colorectal cancer cell lines tended to have longer periods and altered phases compared to the respective normal epithelial cells $[47,50]$. Deviations from period and phase are also seen in our data, where 21PT cells exhibited consistent changes (i.e., $\sim 8 \mathrm{~h}$ phase offset with similar growth rates) for BMAL1 and PER2, while 21MT-1 showed contrasting alterations for the two genes (i.e., $\sim 8 \mathrm{~h}$ phase offset with two opposing growth trends, one increasing and the other decreasing) and the worst sinusoidal curve fits overall. It is surprising to us that 
different cancers can have similar changes in circadian characteristics. Broadly, our results support the hypothesis that circadian rhythms are increasingly disrupted in breast cancer.

Although it is unclear how circadian changes occur in the cancerous 21PT and 21MT-1 cells, molecular profiling of the cells may provide some clues. Several studies have characterized the genetic profiles of cells from the 21T series [30,51-54]. Band et al., showed that compared to normal epithelial H16N2 cells, the others were HER2 positive (overexpressing $E R B B 2$ ) [30]. It is known that $E R B B 2$ is closely associated with NR1D1 [55], the gene that encodes REV-ERB $\alpha$ (a clock protein involved in the secondary clock TTFL), and high levels of NR1D1 have frequently been found in breast cancer patients [56]. In addition to being HER2 positive, 21MT-1 cells had hyper-activated p-Ser ${ }^{473}$ Akt [52], a kinase involved in the PI3K/Akt/mTOR pathway frequently activated in breast cancer [57,58]. AKT phosphorylates CLOCK and BMAL1 and inhibits their nuclear localization [59,60], and the mTOR pathway has been shown to regulate circadian entrainment in the SCN [61]. Taken together, abnormal ERBB2/NR1D1 expression and activated Akt/mTOR pathways may all contribute to the prolonged periods and altered phases of BMAL1 and PER2 in the cancerous 21PT and 21MT-1 cells. Both aspects should be examined further to determine their potential contributions to altered circadian oscillations.

To evaluate whether changes in transcriptional expression can be detected at the translational level, we performed time-course Western blot analyses of BMAL1 and PER2 in the three cell lines from the 21T series. Our results showed that there was no clear and consistent phase relationship between BMAL1 and PER2 in any of them (Figures S1 and S2). Although some statistical analyses revealed rhythmicity in certain expression patterns (Tables S6 and S7), it is likely that the changes were too small to be reliable. Several studies have investigated temporal changes in clock protein expression using different disease models; however, while some showed clear and detectable protein oscillations [62,63], others did not, perhaps due to the low resolution of Western blotting [64,65]. We also noted subtle changes in GAPDH expression over time; however, the minor instability of a reference protein has been shown previously in various cell models $[50,66,67]$.

The poor correlation between observed mRNA and protein expression could also be induced by changes to transcriptional regulation, post-transcriptional modifications, protein half-lives, and technical errors and noise in either or both mRNA and protein experiments [68-70]. As an example, Robles et al., showed that post-transcriptional modifications caused a phase delay of $6 \mathrm{~h}$ between cycling transcripts and corresponding proteins [69]. Future studies with this system should use luciferase reporters to acquire high-resolution data at both the promoter and translational levels, which will enable more detailed visualizations of oscillations and thorough analyses.

\section{Materials and Methods}

\subsection{Cell Culture}

H16N2, 21PT, and 21MT-1 cell lines were obtained from Prof. D. Joseph Jerry (Veterinary and Animal Sciences, UMass Amherst, MA, USA), who received them directly from Dr. Vimla Band, who originally isolated the cells. Cells were maintained in MEM (Gibco, Waltham, MA, USA), with 1\% penicillin-streptomycin (Gibco), 1 mM HEPES (Hyclone, Logan, UT, USA), $1 \mathrm{mM}$ sodium pyruvate (Gibco), $2 \mathrm{mM}$ L-glutamine (Gibco), 10\% fetal bovine serum (FBS; Corning, Corning, NY, USA), $15 \mu \mathrm{g} / \mathrm{mL}$ gentamicin (Fisher Scientific, Waltham, MA, USA), $1 \mu \mathrm{g} / \mathrm{mL}$ insulin (Sigma, St. Louis, MO, USA), $12.5 \mathrm{ng} / \mathrm{mL}$ epidermal growth factor (EGF; Gibco), and $1 \mu \mathrm{g} / \mathrm{mL}$ hydrocortisone (Sigma). All cells were incubated at $37^{\circ} \mathrm{C}$ under $5 \% \mathrm{CO}_{2}$.

\subsection{Synchronization of Cells by Serum Shock}

A $2 \mathrm{~mL}$ volume of cells at a density of $2 \times 10^{5}$ cells $/ \mathrm{mL}$ was plated in $35 \mathrm{~mm}$ culture dishes and incubated for approximately $24 \mathrm{~h}$ to reach $100 \%$ confluence. Culture media were discarded, and cells were washed once with $2 \mathrm{~mL}$ of phosphate-buffered saline (PBS; Gibco). Cells were then starved in MEM medium without any supplements for $12 \mathrm{~h}$. After 
starvation, cells were serum shocked using growth medium containing $50 \%$ FBS for $2 \mathrm{~h}$, followed by a wash with PBS, and returned to starvation conditions (culture in MEM medium without any supplements).

\subsection{RNA Extraction and cDNA Synthesis}

Cells were collected at the first time point immediately following serum shock $(\mathrm{T}=0)$ and every $4 \mathrm{~h}$ thereafter for $48 \mathrm{~h}$. Total RNA was extracted via TRIzol Reagent (Gibco) according to the manufacturer's instructions. Briefly, $1 \mathrm{~mL}$ of TRIzol was added to lyse the cells, and cell lysates were transferred to microcentrifuge tubes. Cell lysates were incubated at rt for $5 \mathrm{~min}$ to allow complete dissociation of nucleoprotein complexes. After the addition of $200 \mu \mathrm{L}$ chloroform per $1 \mathrm{~mL}$ of TRIzol, samples were shaken vigorously by hand for $15 \mathrm{~s}$ and incubated at $\mathrm{rt}$ for $3 \mathrm{~min}$. Samples were then centrifuged at $12,000 \times g$ for $15 \mathrm{~min}$ at $4{ }^{\circ} \mathrm{C}$ to separate the RNA-containing, upper aqueous phase, from the lower chloroform phase. RNA samples were further purified via the PureLink RNA kit (Ambion, Austin, TX, USA) according to the manufacturer's instructions. Total RNA concentration was determined by Nanodrop UV/Vis (Thermo Fisher Scientific, Waltham, MA, USA). A $1 \mu \mathrm{g}$ amount of total RNA was reverse-transcribed to cDNA using $50 \mu \mathrm{M}$ random hexamers, $40 \mathrm{U} / \mu \mathrm{L}$ RNaseOut, 10 mM dNTPs, and $200 \mathrm{U} / \mu \mathrm{L}$ SuperScript IV Reverse Transcriptase (Thermo Fisher Scientific).

\subsection{Real-Time PCR (RT-PCR)}

RT-PCR was performed in 96-well plates. Each reaction $(20 \mu \mathrm{L}$ per well) consisted of 100 ng cDNA, $10 \mu \mathrm{L}$ iTaq universal SYBR Green Supermix (Bio-Rad, Hercules, CA, USA), $4 \mu \mathrm{M}$ of each respective forward and reverse primer, and RNAse free water (Fisher) to a final volume of $20 \mu \mathrm{L}$. All DNA primers were purchased from Integrated DNA Technologies (Coralville, IA, USA). The following sequences were used: GAPDH forward (5'-CTT CTT TTG CGT CGC CAG CC-3'), reverse (5'-ATT CCG TTG ACT CCG ACC TTC-3'); BMAL1 forward (5'-CTA CGC TAG AGG GCT TCC TG-3'), reverse (5'-CTT TTC AGG CGG TCA GCT TC-3'); PER2 forward (5'-TGT CCC AGG TGG AGA GTG GT-3'), reverse (5'-TGT CAC CGC AGT TCA AAC GAG-3'). After brief centrifugation, samples were analyzed via the CFX Connect real-time system (Bio-Rad) programmed with an initial activation at $95^{\circ} \mathrm{C}$ for $3 \mathrm{~min}$, followed by 40 cycles of $95^{\circ} \mathrm{C}$ denaturation for $10 \mathrm{~s}$, and $60{ }^{\circ} \mathrm{C}$ annealing/extension for $30 \mathrm{~s}$. Relative $B M A L 1$ and PER2 expression levels were determined by comparing the $C_{t}$ values of BMAL1 and PER2 to GAPDH controls via the $2^{\wedge} \Delta \Delta C_{t}$ method [71]. Three biological replicates and three technical replicates per biological replicate were analyzed for each condition.

\subsection{Rhythmicity Tests}

Rhythmicity tests were performed using R packages (www.r-project.org). RAIN (rain $\mathrm{v}$ 1.14.0) was used for a period of $24 \mathrm{~h}$. The Lomb-Scargle permutation test (randlsp from lomb package v1.2; using the peak of the periodogram in the range of 6 to $50 \mathrm{~h}$ ) used 5000 random permutations [35]. Metacycle v1.2.0 [72] was used to run the JTK-Cycle test. ECHO (echo.find v3.0) was used to test for periodicity in the range of 24 to $32 \mathrm{~h}$, after linearly de-trending [37]. Following the tests for rhythmicity, a test for differential rhythmicity was used for each pair of cell lines with the DODR R package (v.0.99.2) [38].

\subsection{Curve Fitting}

Each mRNA time series (with 5-6 biological replicates) was fit to a "damped" cosine curve with a linear baseline: $A e^{-\lambda t} \cos \left(2 \pi \frac{t-\theta}{\tau}\right)+m t+b$, where $A$ is amplitude, $\lambda$ is damping rate, $\theta$ is phase, $\tau$ is intrinsic period, $m$ is baseline slope, and $b$ is $y$-intercept. $\lambda$ was allowed to vary between -0.05 (a growing curve) and 0.05 (a damping curve). As in $\mathrm{ECHO}$, each point was weighted by the inverse of the variance at its time step. The $\mathrm{R}$ function nls was used to estimate the coefficients and compute the $95 \%$ confidence intervals. 


\section{Conclusions}

In this study, we report the first findings of circadian disruption in a progressive series of human, breast cancer patient-derived cells. We evaluated the oscillations of mRNA expression for two core clock components, BMAL1 and PER2, in a time-dependent manner, in cell lines across the 21T series. Normal epithelial H16N2 cells displayed standard oscillation patterns. The two cancerous cell types, 21PT and 21MT-1, exhibited periods that deviated farther from $24 \mathrm{~h}$ and were less consistent between the BMAL1 and PER2 transcripts, which were also not anti-phase with the expected $12 \mathrm{~h}$ differences in peak times.

Our analyses of protein expression revealed that neither BMAL1 nor PER2 had clear, anti-phase relationships in any of the cells. This is likely due to the low-resolution feature of Western blotting, where changes were too subtle to be detected. Taken together, our data support the hypothesis that circadian rhythms are increasingly disrupted with malignancy in breast cancer. To provide a better understanding and more accurate analyses of these altered oscillations, luciferase reporters and real-time luminometry should be used in the future. Furthermore, next-generation sequencing can be utilized to assess connections between cancer and circadian pathways, and may provide insights to how they affect one another. Understanding the contributions of circadian rhythms and their effects on breast cancer development will be pivotal to understanding the roles of the clock in this and other diseases.

Supplementary Materials: The following are available online at https: / www.mdpi.com/article/ 10.3390/clockssleep3040042/s1, Table S1: Estimates and confidence intervals for BMAL1 mRNA time series from H16N2. Table S2: Estimates and confidence intervals for PER2 mRNA time series from H16N2. Table S3: Estimates and confidence intervals for BMAL1 mRNA time series from 21PT. Table S4: Estimates and confidence intervals for PER2 mRNA time series from 21PT. Table S5: Estimates and confidence intervals for PER2 mRNA time series from 21MT-1. Table S6: $p$-values from rhythmicity tests for the BMAL1 protein time series. Table S7: $p$-values from rhythmicity tests for the PER2 protein time series. Figure S1: All Western blots for BMAL1 and PER2 for H16N2 cells, 21PT cells, and 21MT-1 cells. Figure S2: Relative protein expression of BMAL1 and PER2 in the 21T series of cells, as determined by Western blot.

Author Contributions: Conceptualization, H.-H.L. and M.E.F.; methodology, H.-H.L.; software, S.R.T.; validation, H.-H.L. and M.E.F.; formal analysis, H.-H.L. and S.R.T.; data curation, H.-H.L., M.E.F. and S.R.T.; writing—original draft preparation, H.-H.L.; writing—review and editing, M.E.F. and S.R.T.; visualization, H.-H.L.; supervision, M.E.F.; project administration, M.E.F.; funding acquisition, M.E.F. All authors have read and agreed to the published version of the manuscript.

Funding: H.-H.L. was supported by a University of Massachusetts Amherst Chemistry-Biology Interface (CBI) training fellowship (National Research Service Award T32 GM008515 from the National Institutes of Health). This work was funded in part by the National Institute of General Medical Sciences of the National Institutes of Health under Award Number R35GM143016.

Institutional Review Board Statement: Not applicable.

Informed Consent Statement: Not applicable.

Data Availability Statement: Raw data are available from the authors upon request.

Acknowledgments: We are grateful to the laboratory of D. Joseph Jerry (Veterinary and Animal Sciences, UMass Amherst) for providing cell lines and culture protocols. We would like to thank Bharath Ananthasubramaniam (Institute for Theoretical Biology, Charite-Universitätsmedizin Berlin), Tanya Leise (Mathematics and Statistics, Amherst College), Jennifer Hurley (Biological Sciences, Rensselaer Polytechnic Institute), and Hannah De Los Santos (Computer Science, Rensselaer Polytechnic Institute) for helpful discussions regarding analyses, and Sujeewa Lellupitiyage Don (Chemistry, UMass Amherst) for assistance in manuscript preparation. We are also grateful to the laboratory of Elizabeth Vierling (Biochemistry and Molecular Biology, UMass Amherst) for G:Box iChemi XT imaging system (GeneSys) access.

Conflicts of Interest: The authors declare no conflict of interest. 


\section{References}

1. Dierickx, P.; Van Laake, L.W.; Geijsen, N. Circadian clocks: From stem cells to tissue homeostasis and regeneration. EMBO Rep. 2018, 19, 18-28. [CrossRef]

2. Partch, C.L.; Green, C.B.; Takahashi, J.S. Molecular architecture of the mammalian circadian clock. Trends Cell Biol. 2014, 24, 90-99. [CrossRef] [PubMed]

3. Janich, P.; Toufighi, K.; Solanas, G.; Luis, N.M.; Minkwitz, S.; Serrano, L.; Lehner, B.; Benitah, S.A. Human epidermal stem cell function is regulated by circadian oscillations. Cell Stem Cell 2013, 13, 745-753. [CrossRef]

4. Gaucher, J.; Montellier, E.; Sassone-Corsi, P. Molecular cogs: Interplay between circadian clock and cell cycle. Trends Cell Biol. 2018, 28, 368-379. [CrossRef] [PubMed]

5. Blakeman, V.; Williams, J.L.; Meng, Q.-J.; Streuli, C.H. Circadian clocks and breast cancer. Breast Cancer Res. 2016, 18, 89. [CrossRef]

6. Cadenas, C.; van de Sandt, L.; Edlund, K.; Lohr, M.; Hellwig, B.; Marchan, R.; Schmidt, M.; Rahnenführer, J.; Oster, H.; Hengstler, J.G. Loss of circadian clock gene expression is associated with tumor progression in breast cancer. Cell Cycle 2014, 13, 3282-3291. [CrossRef]

7. Chen, S.-T.; Choo, K.-B.; Hou, M.-F.; Yeh, K.-T.; Kuo, S.-J.; Chang, J.-G. Deregulated expression of the PER1, PER2, and PER3 genes in breast cancers. Carcinogenesis 2005, 26, 1241-1246. [CrossRef]

8. Gutiérrez-Monreal, M.A.; Treviño, V.; Moreno-Cuevas, J.E.; Scott, S.-P. Identification of circadian-related gene expression profiles in entrained breast cancer cell lines. Chronobiol. Int. 2016, 33, 392-405. [CrossRef] [PubMed]

9. Krugluger, W.; Brandstaetter, A.; Kállay, E.; Schueller, J.; Krexner, E.; Kriwanek, S.; Bonner, E.; Cross, H.S. Regulation of genes of the circadian clock in human colon cancer: Reduced period-1 and dihydropyrimidine dehydrogenase transcription correlates in high-grade tumors. Cancer Res. 2007, 67, 7917-7922. [CrossRef]

10. Kloog, I.; Haim, A.; Stevens, R.G.; Portnov, B.A. Global co-distribution of light at night (LAN) and cancers of prostate, colon, and lung in men. Chronobiol. Int. 2009, 26, 108-125. [CrossRef]

11. Davis, S.; Mirick, D.K.; Stevens, R.G. Night shift work, light at night, and risk of breast cancer. J. Natl. Cancer Inst. 2001, 93, 1557-1562. [CrossRef] [PubMed]

12. Fritschi, L.; Erren, T.C.; Glass, D.C.; Girschik, J.; Thomson, A.K.; Saunders, C.; Boyle, T.; El-Zaemey, S.; Rogers, P.; Peters, S.; et al. The association between different night shiftwork factors and breast cancer: A case-control study. Br. J. Cancer 2013, 109, 2472-2480. [CrossRef] [PubMed]

13. Lin, H.-H.; Farkas, M.E. Altered circadian rhythms and breast cancer: From the human to the molecular level. Front. Endocrinol. 2018, 9, 219. [CrossRef] [PubMed]

14. Siegel, R.L.; Miller, K.D.; Jemal, A. Cancer statistics, 2019. CA A Cancer J. Clin. 2019, 69, 7-34. [CrossRef] [PubMed]

15. Muschler, J.; Streuli, C.H. Cell-matrix interactions in mammary gland development and breast cancer. Cold Spring Harb. Perspect. Biol. 2010, 2, a003202. [CrossRef]

16. Ma, H.; Henderson, K.D.; Sullivan-Halley, J.; Duan, L.; Marshall, S.F.; Ursin, G.; Horn-Ross, P.L.; Largent, J.; Deapen, D.M.; Lacey, J.V.; et al. Pregnancy-related factors and the risk of breast carcinoma in situand invasive breast cancer among postmenopausal women in the California Teachers Study cohort. Breast Cancer Res. 2010, 12, R35. [CrossRef]

17. Lanigan, F.; O'Connor, D.; Martin, F.; Gallagher, W.M. Common molecular mechanisms of mammary gland development and breast cancer. Cell. Mol. Life Sci. 2007, 64, 3159-3184. [CrossRef]

18. Ercan, C.; van Diest, P.J.; Vooijs, M. Mammary development and breast cancer: The role of stem cells. Curr Mol. Med. 2011, 11, 270-285. [CrossRef]

19. Karsli-Ceppioglu, S.; Dagdemir, A.; Judes, G.; Ngollo, M.; Penault-Llorca, F.; Pajon, A.; Bignon, Y.-J.; Bernard-Gallon, D. Epigenetic mechanisms of breast cancer: An update of the current knowledge. Epigenomics 2014, 6, 651-664. [CrossRef]

20. Takeshima, H.; Ushijima, T. Accumulation of genetic and epigenetic alterations in normal cells and cancer risk. NPJ Precis. Oncol. 2019, 3, 7. [CrossRef]

21. Comşa, Ş.; Cîmpean, A.M.; Raica, M. The Story of MCF-7 breast cancer cell line: 40 years of experience in research. Anticancer Res. 2015, 35, 3147-3154. [PubMed]

22. Razak, N.A.; Abu, N.; Ho, W.Y.; Zamberi, N.R.; Tan, S.W.; Alitheen, N.B.; Long, K.; Yeap, S.K. Cytotoxicity of eupatorin in MCF-7 and MDA-MB-231 human breast cancer cells via cell cycle arrest, anti-angiogenesis and induction of apoptosis. Sci. Rep. 2019, 9, 1514. [CrossRef] [PubMed]

23. Brigger, D.; Schläfli, A.M.; Garattini, E.; Tschan, M.P. Activation of RAR $\alpha$ induces autophagy in SKBR3 breast cancer cells and depletion of key autophagy genes enhances ATRA toxicity. Cell Death Dis. 2015, 6, e1861. [CrossRef] [PubMed]

24. Dai, X.; Cheng, H.; Bai, Z.; Li, J. Breast cancer cell line classification and its relevance with breast tumor subtyping. J. Cancer 2017, 8, 3131-3141. [CrossRef] [PubMed]

25. Soule, H.D.; Maloney, T.M.; Wolman, S.R.; Peterson, W.D.; Brenz, R.; McGrath, C.M.; Russo, J.; Pauley, R.J.; Jones, R.F.; Brooks, S.C. Isolation and characterization of a spontaneously immortalized human breast epithelial cell line, MCF-10. Cancer Res. 1990, 50, 6075-6086. [PubMed]

26. Dawson, P.J.; Wolman, S.R.; Tait, L.; Heppner, G.H.; Miller, F.R. MCF10AT: A model for the evolution of cancer from proliferative breast disease. Am. J. Pathol. 1996, 148, 313-319. [PubMed] 
27. Santner, S.J.; Dawson, P.J.; Tait, L.; Soule, H.D.; Eliason, J.; Mohamed, A.N.; Wolman, S.R.; Heppner, G.H.; Miller, F.R. Malignant MCF10CA1 cell lines derived from premalignant human breast epithelial MCF10AT Cells. Breast Cancer Res. Treat. 2001, 65, 101-110. [CrossRef] [PubMed]

28. Yang, J.; Mani, S.A.; Donaher, J.L.; Ramaswamy, S.; Itzykson, R.A.; Come, C.; Savagner, P.; Gitelman, I.; Richardson, A.; Weinberg, R.A. Twist, a master regulator of morphogenesis, plays an essential role in tumor metastasis. Cell 2004, 117, 927-939. [CrossRef] [PubMed]

29. Aslakson, C.J.; Miller, F.R. Selective events in the metastatic process defined by analysis of the sequential dissemination of subpopulations of a mouse mammary tumor. Cancer Res. 1992, 52, 1399-1405. [PubMed]

30. Band, V.; Zajchowski, D.; Swisshelm, K.; Trask, D.; Kulesa, V.; Cohen, C.; Connolly, J.; Sager, R. Tumor progression in four mammary epithelial cell lines derived from the same patient. Cancer Res. 1990, 50, 7351-7357. [PubMed]

31. Kumar, R.; Yarmand-Bagheri, R. The role of HER2 in angiogenesis. Semin. Oncol. 2001, 28, 27-32. [CrossRef]

32. Tai, W.; Mahato, R.; Cheng, K. The role of HER2 in cancer therapy and targeted drug delivery. J. Control. Release 2010, 146, 264-275. [CrossRef]

33. Lin, H.-H.; Qraitem, M.; Lian, Y.; Taylor, S.R.; Farkas, M.E. Analyses of BMAL1 and PER2 oscillations in a model of breast cancer progression reveal changes with malignancy. Integr. Cancer Ther. 2019, 18, 1534735419836494. [CrossRef] [PubMed]

34. Thaben, P.F.; Westermark, P.O. Detecting rhythms in time series with RAIN. J. Biol. Rhythm. 2014, 29, 391-400. [CrossRef] [PubMed]

35. Ruf, T. The Lomb-Scargle periodogram in biological rhythm research: Analysis of incomplete and unequally spaced time-series. Biol. Rhythm Res. 1999, 30, 178-201. [CrossRef]

36. Hughes, M.E.; Hogenesch, J.B.; Kornacker, K. JTK_CYCLE: An efficient nonparametric algorithm for detecting rhythmic components in genome-scale data sets. J. Biol. Rhythm. 2010, 25, 372-380. [CrossRef]

37. De los Santos, H.; Collins, E.J.; Mann, C.; Sagan, A.W.; Jankowski, M.S.; Bennett, K.P.; Hurley, J.M. ECHO: An application for detection and analysis of oscillators identifies metabolic regulation on genome-wide circadian output. Bioinformatics 2019, 36, 773-781. [CrossRef] [PubMed]

38. Thaben, P.F.; Westermark, P.O. Differential rhythmicity: Detecting altered rhythmicity in biological data. Bioinformatics 2016, 32, 2800-2808. [CrossRef]

39. Yang, X.; Wood, P.A.; Oh, E.-Y.; Du-Quiton, J.; Ansell, C.M.; Hrushesky, W.J.M. Down regulation of circadian clock gene Period 2 accelerates breast cancer growth by altering its daily growth rhythm. Breast Cancer Res. Treat. 2009, 117, 423-431. [CrossRef]

40. Matsunaga, N.; Ogino, T.; Hara, Y.; Tanaka, T.; Koyanagi, S.; Ohdo, S. Optimized dosing schedule based on circadian dynamics of mouse breast cancer stem cells improves the antitumor effects of aldehyde dehydrogenase inhibitor. Cancer Res. 2018, 78, 3698-3708. [CrossRef]

41. Rossetti, S.; Esposito, J.; Corlazzoli, F.; Gregorski, A.; Sacchi, N. Entrainment of breast (cancer) epithelial cells detects distinct circadian oscillation patterns for clock and hormone receptor genes. Cell Cycle 2012, 11, 350-360. [CrossRef]

42. Lellupitiyage Don, S.S.; Lin, H.-H.; Furtado, J.J.; Qraitem, M.; Taylor, S.R.; Farkas, M.E. Circadian oscillations persist in low malignancy breast cancer cells. Cell Cycle 2019, 18, 2447-2453. [CrossRef]

43. Borniger, J.C.; Walker, W.H., II; Surbhi; Emmer, K.M.; Zhang, N.; Zalenski, A.A.; Muscarella, S.L.; Fitzgerald, J.A.; Smith, A.N.; Braam, C.J.; et al. A role for hypocretin/orexin in metabolic and sleep abnormalities in a mouse model of non-metastatic breast cancer. Cell Metab. 2018, 28, 118-129. [CrossRef]

44. Lesicka, M.; Jablonska, E.; Wieczorek, E.; Seroczynska, B.; Siekierzycka, A.; Skokowski, J.; Kalinowski, L.; Wasowicz, W.; Reska, E. Altered circadian genes expression in breast cancer tissue according to the clinical characteristics. PLoS ONE 2018, 13, e0199622. [CrossRef]

45. Hoffman, A.E.; Zheng, T.; Yi, C.-H.; Stevens, R.G.; Ba, Y.; Zhang, Y.; Leaderer, D.; Holford, T.; Hansen, J.; Zhu, Y. The core circadian gene Cryptochrome 2 influences breast cancer risk, possibly by mediating hormone signaling. Cancer Prev. Res. 2010, 3, 539-548. [CrossRef]

46. Harbour, V.L.; Weigl, Y.; Robinson, B.; Amir, S. Phase differences in expression of circadian clock genes in the central nucleus of the amygdala, dentate gyrus, and suprachiasmatic nucleus in the rat. PLoS ONE 2014, 9, e103309. [CrossRef] [PubMed]

47. Relógio, A.; Thomas, P.; Medina-Pérez, P.; Reischl, S.; Bervoets, S.; Gloc, E.; Riemer, P.; Mang-Fatehi, S.; Maier, B.; Schäfer, R.; et al. Ras-mediated deregulation of the circadian clock in cancer. PLoS Genet. 2014, 10, e1004338. [CrossRef] [PubMed]

48. Huisman, S.A.; Oklejewicz, M.; Ahmadi, A.R.; Tamanini, F.; Ijzermans, J.N.M.; van der Horst, G.T.J.; de Bruin, R.W.F. Colorectal liver metastases with a disrupted circadian rhythm phase shift the peripheral clock in liver and kidney. Int. J. Cancer 2015, 136, 1024-1032. [CrossRef] [PubMed]

49. Pati, A.K.; Parganiha, A.; Kar, A.; Soni, R.; Roy, S.; Choudhary, V. Alterations of the characteristics of the circadian rest-activity rhythm of cancer in-patients. Chronobiol. Int. 2007, 24, 1179-1197. [CrossRef]

50. Fuhr, L.; El-Athman, R.; Scrima, R.; Cela, O.; Carbone, A.; Knoop, H.; Li, Y.; Hoffmann, K.; Laukkanen, M.O.; Corcione, F.; et al. The circadian clock regulates metabolic phenotype rewiring Via HKDC1 and modulates tumor progression and drug response in colorectal cancer. EBioMedicine 2018, 33, 105-121. [CrossRef]

51. Souter, L.H.; Andrews, J.D.; Zhang, G.; Cook, A.C.; Postenka, C.O.; Al-Katib, W.; Leong, H.S.; Rodenhiser, D.I.; Chambers, A.F.; Tuck, A.B. Human 21T breast epithelial cell lines mimic breast cancer progression in vivo and in vitro and show stage-specific gene expression patterns. Lab. Investig. 2010, 90, 1247-1258. [CrossRef] 
52. Qiao, M.; Iglehart, J.D.; Pardee, A.B. Metastatic potential of 21T human breast cancer cells depends on Akt/Protein Kinase B activation. Cancer Res. 2007, 67, 5293-5299. [CrossRef]

53. Santos Jr, G.C.; da Silva, A.P.A.; Feldman, L.; Ventura, G.M.; Vassetzky, Y.; de Moura Gallo, C.V. Epigenetic modifications, chromatin distribution and TP53 transcription in a model of breast cancer progression. J. Cell. Biochem. 2015, 116, 533-541. [CrossRef]

54. Stankevicins, L.; Barat, A.; Dessen, P.; Vassetzky, Y.; de Moura Gallo, C.V. The microRNA-205-5p is correlated to metastatic potential of 21T series: A breast cancer progression model. PLoS ONE 2017, 12, e0173756. [CrossRef]

55. Kourtidis, A.; Jain, R.; Carkner, R.D.; Eifert, C.; Brosnan, M.J.; Conklin, D.S. An RNA interference screen identifies metabolic regulators NR1D1 and PBP as novel survival factors for breast cancer cells with the ERBB2 signature. Cancer Res. 2010, 70, 1783-1792. [CrossRef]

56. Na, H.; Han, J.; Ka, N.-L.; Lee, M.-H.; Choi, Y.-L.; Shin, Y.K.; Lee, M.-O. High expression of NR1D1 is associated with good prognosis in triple-negative breast cancer patients treated with chemotherapy. Breast Cancer Res. 2019, 21, 127. [CrossRef] [PubMed]

57. Lee, J.J.; Loh, K.; Yap, Y.-S. PI3K/Akt/mTOR inhibitors in breast cancer. Cancer Biol Med. 2015, 12, 342-354. [CrossRef] [PubMed]

58. McAuliffe, P.F.; Meric-Bernstam, F.; Mills, G.B.; Gonzalez-Angulo, A.M. Deciphering the role of PI3K/Akt/mTOR pathway in breast cancer biology and pathogenesis. Clin. Breast Cancer 2010, 10, S59-S65. [CrossRef] [PubMed]

59. Luciano, A.K.; Zhou, W.; Santana, J.M.; Kyriakides, C.; Velazquez, H.; Sessa, W.C. CLOCK phosphorylation by AKT regulates its nuclear accumulation and circadian gene expression in peripheral tissues. J. Biol. Chem. 2018, 293, 9126-9136. [CrossRef]

60. Dang, F.; Sun, X.; Ma, X.; Wu, R.; Zhang, D.; Chen, Y.; Xu, Q.; Wu, Y.; Liu, Y. Insulin post-transcriptionally modulates Bmal1 protein to affect the hepatic circadian clock. Nat. Commun. 2016, 7, 12696. [CrossRef] [PubMed]

61. Cao, R. mTOR signaling, translational control, and the circadian clock. Front. Genet. 2018, 9, 367. [CrossRef] [PubMed]

62. Tang, Q.; Xie, M.; Yu, S.; Zhou, X.; Xie, Y.; Chen, G.; Guo, F.; Chen, L. Periodic oxaliplatin administration in synergy with PER2-mediated PCNA transcription repression promotes chronochemotherapeutic efficacy of OSCC. Adv. Sci. 2019, 6, 1900667. [CrossRef]

63. Altman, B.J.; Hsieh, A.L.; Sengupta, A.; Krishnanaiah, S.Y.; Stine, Z.E.; Walton, Z.E.; Gouw, A.M.; Venkataraman, A.; Li, B.; Goraksha-Hicks, P.; et al. MYC disrupts the circadian clock and metabolism in cancer cells. Cell Metab. 2015, 22, 1009-1019. [CrossRef] [PubMed]

64. Song, H.; Moon, M.; Choe, H.K.; Han, D.-H.; Jang, C.; Kim, A.; Cho, S.; Kim, K.; Mook-Jung, I. A $\beta$-induced degradation of BMAL1 and CBP leads to circadian rhythm disruption in Alzheimer's disease. Mol. Neurodegener. 2015, 10, 13. [CrossRef] [PubMed]

65. Tan, H.; Zhu, Y.; Zheng, X.; Lu, Y.; Tao, D.; Liu, Y.; Ma, Y. PIWIL1 suppresses circadian rhythms through GSK3 $\beta$-induced phosphorylation and degradation of CLOCK and BMAL1 in cancer cells. J. Cell. Mol. Med. 2019, 23, 4689-4698. [CrossRef]

66. Andrews, J.L.; Zhang, X.; McCarthy, J.J.; McDearmon, E.L.; Hornberger, T.A.; Russell, B.; Campbell, K.S.; Arbogast, S.; Reid, M.B.; Walker, J.R.; et al. CLOCK and BMAL1 regulate MyoD and are necessary for maintenance of skeletal muscle phenotype and function. Proc. Natl. Acad. Sci. USA 2010, 107, 19090-19095. [CrossRef]

67. Xu, H.; Gustafson, C.L.; Sammons, P.J.; Khan, S.K.; Parsley, N.C.; Ramanathan, C.; Lee, H.-W.; Liu, A.C.; Partch, C.L. Cryptochrome 1 regulates the circadian clock through dynamic interactions with the BMAL1 C terminus. Nat. Struct. Mol. Biol. 2015, 22, 476-484. [CrossRef]

68. Maier, T.; Güell, M.; Serrano, L. Correlation of mRNA and protein in complex biological samples. FEBS Lett. 2009, 583, 3966-3973. [CrossRef]

69. Robles, M.S.; Cox, J.; Mann, M. In-vivo quantitative proteomics reveals a key contribution of post-transcriptional mechanisms to the circadian regulation of liver metabolism. PLoS Genet. 2014, 10, e1004047. [CrossRef]

70. Liu, Y.; Beyer, A.; Aebersold, R. On the dependency of cellular protein levels on mRNA abundance. Cell 2016, 165, 535-550. [CrossRef]

71. Livak, K.J.; Schmittgen, T.D. Analysis of relative gene expression data using real-time quantitative PCR and the $2^{-\Delta \Delta C T}$ method. Methods 2001, 25, 402-408. [CrossRef] [PubMed]

72. Wu, G.; Anafi, R.C.; Hughes, M.E.; Kornacker, K.; Hogenesch, J.B. MetaCycle: An integrated R package to evaluate periodicity in large scale data. Bioinformatics 2016, 32, 3351-3353. [CrossRef] [PubMed] 